\title{
Nipple Ultrasound: A Pictorial Essay
}

\author{
Angelica Chiorean, MD, PhD ${ }^{1,2 *}$, Roxana Maria Pintican, MD ${ }^{1,3 *}$, Madalina Szep, MD, PhD ${ }^{1,2}$, \\ Diana Feier, $M D$, $P h D^{1,2}$, Liliana Rogojan, $M D^{4}$, Bogdan Fetica, $\mathrm{MD}^{4,5}$, George Dindelegan, $M D, \mathrm{PhD}^{6}$, \\ Bura Vlad, MD³, Magdalena Duma, MD, $\mathrm{PhD}^{1,2,7}$
}

\begin{abstract}
${ }^{1}$ Department of Radiology, Iuliu Hațieganu University of Medicine and Pharmacy, Cluj-Napoca, Romania; ${ }^{2}$ Medimages Breast Center, Cluj-Napoca, Romania; Departments of ${ }^{3}$ Radiology and Medical Imaging, ${ }^{4}$ Pathology, and ${ }^{6}$ Surgery, County Clinical Emergency Hospital, Cluj-Napoca, Romania; ${ }^{5}$ Department of Pathology, Ion Chiricuță Oncology Institute, Cluj-Napoca, Romania; ${ }^{7}$ Department of Radiology, Micromedica Clinic, Piatra Neamt, Romania
\end{abstract}

Ultrasound (US) is an attractive diagnostic approach to identify both common and uncommon nipple pathologies, such as duct ectasia, nipple abscess, nipple leiomyoma, nipple adenoma, fibroepithelial polyp, ductal carcinoma in situ (restricted to nipple), invasive carcinoma, and Paget's disease. US is the reliable first-line imaging technique to assess nipple pathologies. It is useful to identify and characterize nipple lesions. Additionally, we have presented the mammography and MRI outcomes correlated with histopathologic features for the relevant cases.

Keywords: Nipple; Ultrasound; Nipple leiomyoma; Nipple adenoma; Nipple ductal carcinoma in situ; DCIS; Paget's disease

\section{INTRODUCTION}

The nipple is an intricate anatomic structure with unique characteristics when compared to other parts of the breast. It is comprised of lactiferous ducts lined by stratified squamous epithelium and dense fibrous stroma with smooth muscle tissue and sebaceous glands $(1,2)$. Pathological processes can arise from any of these structures.

\section{Clinical Examination}

Most patients with nipple pathologies typically present with the associated symptoms upon clinical examination (3). The magnifying lamp is a useful tool to inspect nipple

Received: November 5, 2019 Revised: March 7, 2020

Accepted: March 9, 2020

*Angelica Chiorean and Roxana Maria Pintican equally contributed to this work as co-first authors.

Corresponding author: Roxana Maria Pintican, MD, Department of Radiology, Iuliu Hatieganu University of Medicine and Pharmacy,

Victor Babeș Street, Nr. 8, Cluj-Napoca 400000, Romania.

- Tel: (40) 729121122 • Fax: (40) 264-597-257

- E-mail: roxana.pintican@gmail.com

This is an Open Access article distributed under the terms of the Creative Commons Attribution Non-Commercial License (https://creativecommons.org/licenses/by-nc/4.0) which permits unrestricted non-commercial use, distribution, and reproduction in any medium, provided the original work is properly cited. discharge and changes in nipple skin, shape, volume, and symmetry. Characteristically, a bilateral or long-standing nipple retraction is benign, while the presence of an acquired unilateral nipple inversion implies an underlying malignancy and should be evaluated with various imaging techniques. Furthermore, a benign process is indicated by a central, slit-like nipple retraction, while malignancy typically produces whole nipple inversion associated with areola distortion (2). Skin changes include erythema, ulceration, edema or satellite skin nodules. Therefore, it is difficult to distinguish malignant from benign inflammatory skin changes through a visual inspection (4). Skin changes in breast cancer patients are of prognostic importance, as they function as indicators of upstage to locally advanced cancer (stage T4b) (5).

Imaging assessment of the nipple entails various imaging techniques, such as mammography, ultrasound (US), and MRI. Although a routine mammography has a limited role in evaluating the nipple, it cannot be replaced due to its necessity in identifying calcifications in the breast. Currently, US and magnetic resonance imaging (MRI) are applied to ensure a higher diagnostic accuracy (6-9). US is a necessary technique to assess nipple pathology since it can be used to identify and characterize nipple lesions, distinguish benign and malignant lesions, and guide the management of nipple pathology by facilitating US-guided 
percutaneous biopsy or planning the surgical excision of the lesion(s). US examinations often involve the use of a linear, high frequency transducer $(17-5-\mathrm{MHz})$ that provides excellent superficial soft tissue resolution (10).

The nipple is always assessed bilaterally, using a generous amount of jelly, and visualizing the tissues in the transverse and longitudinal scan planes. If an intraductal lesion is suspected, a radial scan should be performed to apply different angles of the transducer, until the probe is placed parallel to the long axis of the intraductal lesion. Successive compression on the distal and proximal ends of the transducer flattens the nipple to display the extent of the involved duct and its connection to the nipple $(11,12)$.

Doppler mode, strain, and shear-wave elastography increase the specificity of conventional B-mode US and improve its diagnostic performance with regard to both benign and malignant breast lesions $(10,13,14)$. The role of elastography for nipple evaluation is limited due to its superficial location. To the best of our knowledge, there are no currently available recommendations with regard to elastography acquisition for nipple evaluation. Here, we illustrate the importance of US in identifying the normal, benign, and malignant changes in the nipple that typically present as diagnostic difficulties for radiologists.

\section{Normal Findings and Benign Pathology}

\section{Normal Nipple}

Appearance of a normal nipple on US varies among individuals. Nipples frequently demonstrate a homogeneous echo-structure with milk that appear as linear hypo/ isoechoic structures radiating from the nipple towards the breast. Occasionally, the nipple may display scattered hyperechoic foci because the walls of the terminal ducts are typically too small to be observed as tubular fluid-filled

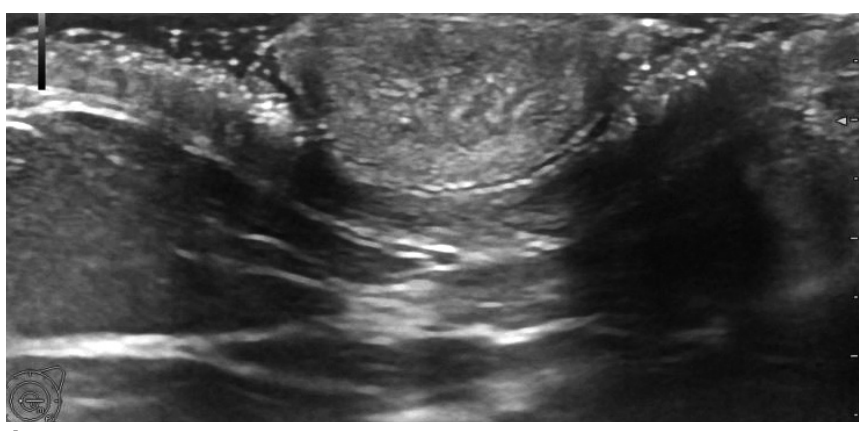

A

Fig. 1. Normal nipple US findings.

Nipple with homogeneous structure on axial (A) and longitudinal (B) planes, with visible longitudinal milk duct $(\mathbf{B}$, arrow). US = ultrasound structures. The latter finding produces a "dots appearance" of the nipple. The variations in the nipple echo-structures can be attributed to differences in the wall thickness of the ducts and differences in the distribution of muscle fibers and connective tissues (Fig. 1). A nipple can be either hypovascular or hypervascular on color Doppler US. Vascular symmetricity a key feature to distinguish normal and pathological nipples. Furthermore, there may be nipple variations including the congenital nipple retraction or accessory nipple (polythelia). During pregnancy and lactation, the areolae and nipples appear darker and larger, due to the underlying benign changes such as nipple crack and erosions (15) (Fig. 2).

\section{Duct Ectasia}

Although it is understood that the prevalence of duct ectasia in nonlactating women rises to $3 \%$ and is responsible for $41 \%$ of the nipple discharge symptoms in women (16), its associated etiology requires further

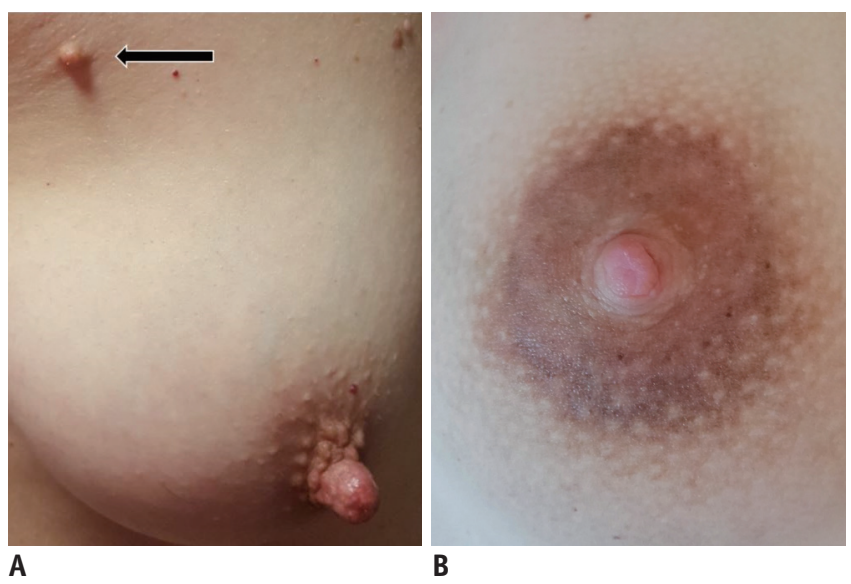

Fig. 2. Polythelia and lactating nipple.

A. There is supernumerary nipple (arrow), located near right axilla, along embryonic milk lines, in consistence with polythelia. B. Darker areola and nipple with prominent Montgomery glands due to lactation. 


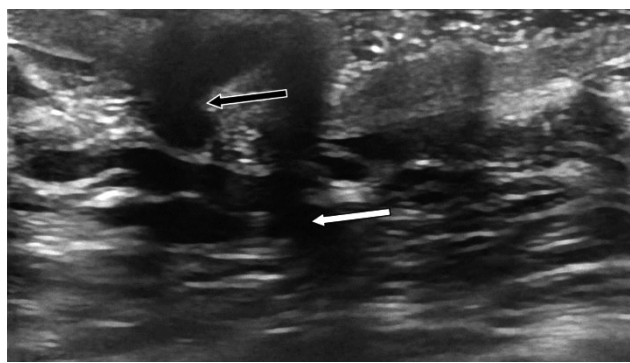

A
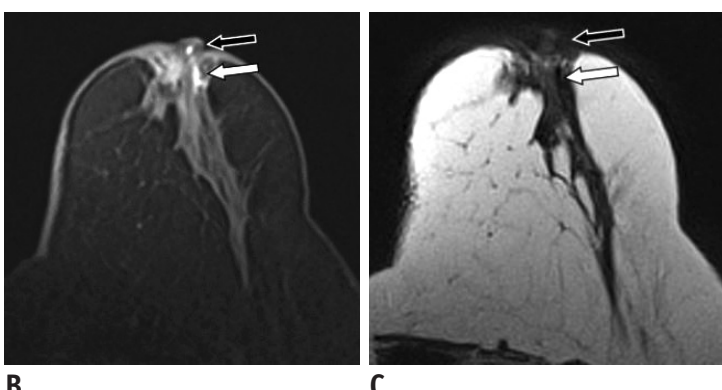

C

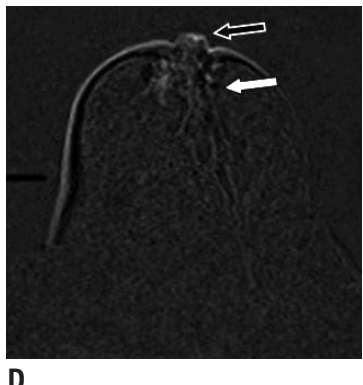

D

Fig. 3. Duct ectasia. 70-year-old woman presented with bloody nipple discharge.

A. US shows dilated ducts within left nipple (black arrow) and retroareolar space (white arrow). Dilated ducts have intermediate T2-weighted signal (C, arrows) and hyperintense signal on T1-weighted fat-saturation non-enhanced image (B, arrows) consistent of blood products. D. No intraductal mass was noted on subtracted enhanced T1-weighted sequence (arrows). Patient refused duct excision and opted for short-term follow-up.

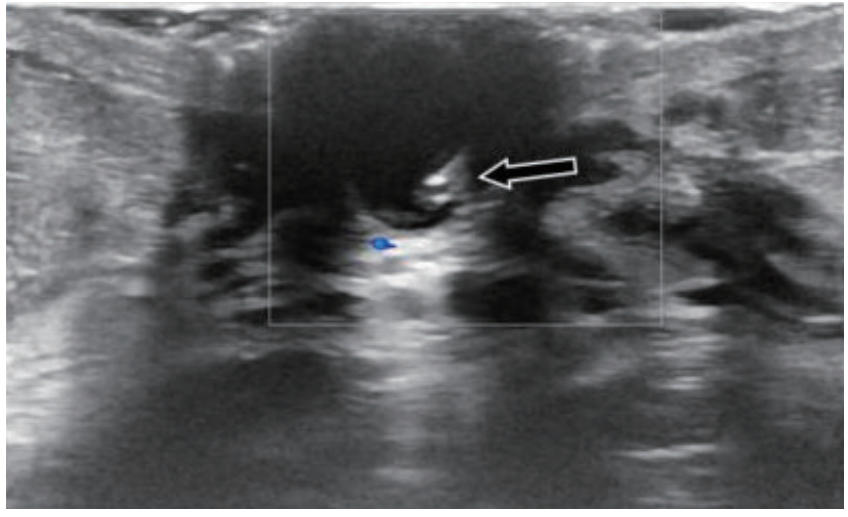

Fig. 4. Galactophoritis. 51-year-old woman presented with serous nipple discharge and nipple pain. US shows dilated duct within left nipple, with hypoechoic content and absent vascularity (arrow). Patient underwent antibiotics therapy with complete resolution of symptoms after 7 days.

elucidation. Duct ectasia is a nonspecific dilatation ( $>2 \mathrm{~mm}$ diameter) of one or more ducts and is typically observed in combination with inflammation (galactophoritis), obstruction, or stasis. Duct excision can be considered in patients with persistent nipple discharge.

US reveals duct changes represented by dilated ducts with anechoic content, corresponding to a high signal intensity on T2-weighted MRI (Fig. 3). Hypoechoic intraductal content is occasionally observed due to viscous secretions or underlying infections. Galactophoritis should be suspected in the presence of inflammatory symptoms (redness, tenderness, pain), and antibiotics should be promptly administered (Fig. 4).

The hypoechoic intraductal content may mimic an intraductal mass (15). In such cases, it is useful to apply repetitive pushing maneuvers on the duct, forcing the viscous secretions to move back and forth within the duct lumen. Color Doppler US is used to distinguish between secretions and intraductal neoplasms. Although secretions do not show internal vascularity, an intraductal neoplasm has internal vascular flow and does not move when subjected to the pushing maneuvers. Scanning duct ectasia is usually accompanied by finding an intraductal neoplasm (Fig. 5). Histological confirmation is imperative when an intraductal neoplasm is suspected, regardless of its location.

\section{Infection and Abscess}

Lactating women are more susceptible to breast infections (mastitis), with the prevalence ranging from $1 \%$ to $10 \%$, than non-lactating women (17). Breast abscesses, which develop as a complication of mastitis, are classified as lactation and non-lactation abscesses. A non-lactation abscess is observed in approximately $90 \%$ of the cases in the sub-areolar area and the nipple (17). An abscess is an accumulation of pus that arises due to an obstructed Montgomery gland. US imaging outcomes present abscesses as a round, iso-/hypoechoic, mass with circumscribed or indistinct margins. The mass is devoid of an internal flow, but demonstrates an intense vascular rim. MRI examinations reveal a T2 hyperintense cystic lesion exhibiting rimenhancement on post-contrast sequences (Fig. 6). Due to superficial location of the nipple, the diffusion-weighted imaging/apparent diffusion coefficient features are not always reliable.

Women with painful nipples may present with pseudosolid looking masses with a vascular rim, which may have occurred due to inflammatory cysts, intra-nipple periductitis, or abscesses. It is not always possible to differentiate these three entities accurately; however, since the management modalities for all three are identical, their differentiation is not particularly important. The lesions respond to anti-inflammatory or antibiotic therapy and 


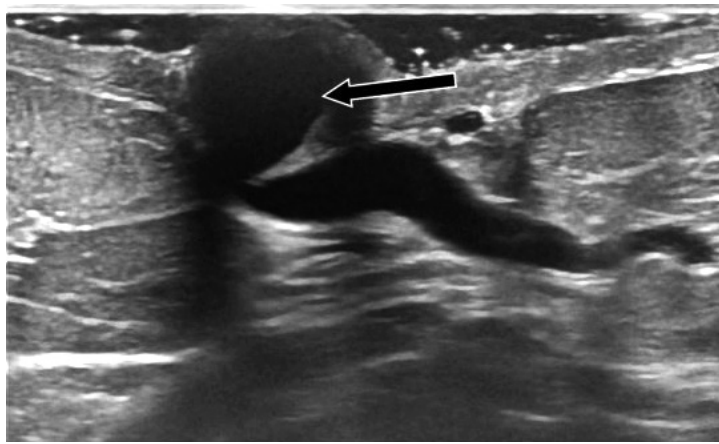

A

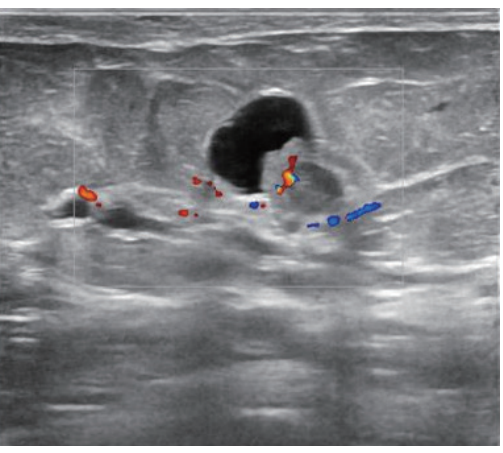

B

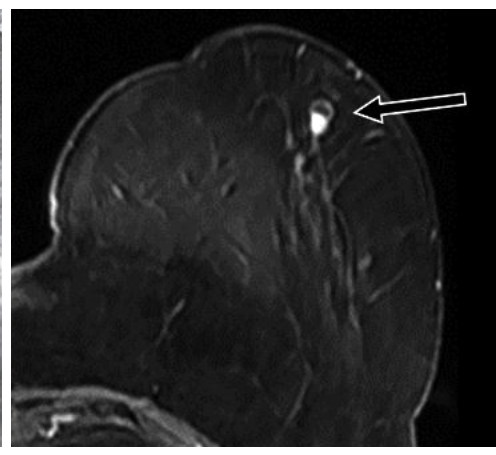

C

Fig. 5. Nipple ectasia combining intraductal neoplasm. 62-year-old woman presented with bloody nipple discharge.

A. US shows dilated duct within nipple (arrow), which extends into retroareolar area. B. Following duct ectasia, complex cystic-solid mass with internal vascularity is found in left-outer quadrant of breast. C. Lesion was confirmed on T1-weighted fat-saturation contrast-enhanced MRI sequence (arrow). Histology revealed intracystic papilloma (not shown).

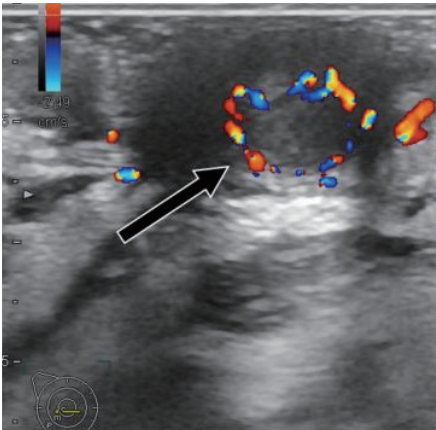

A

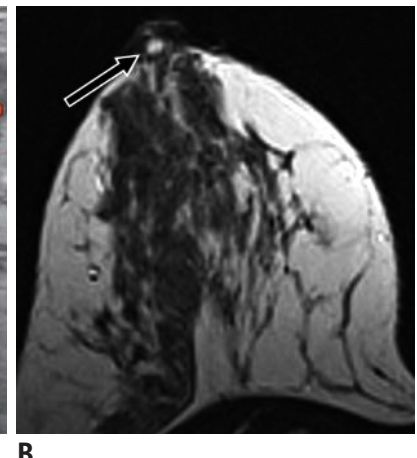

B

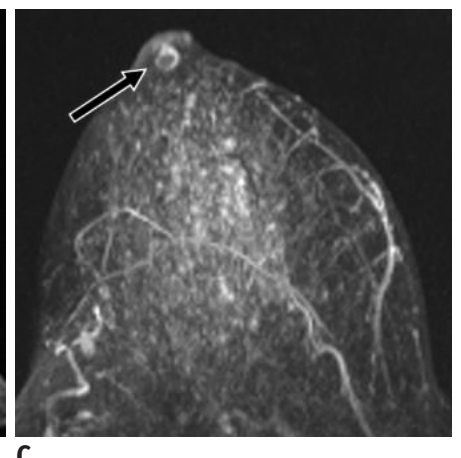

C

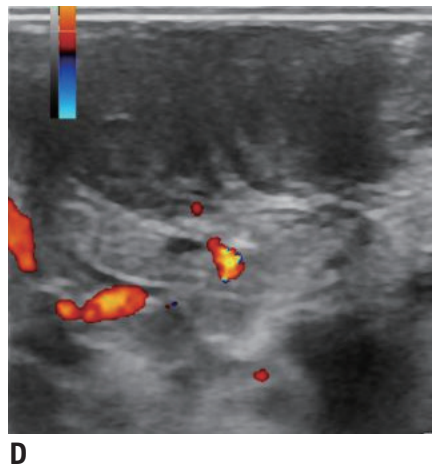

Fig. 6. Nipple abscess. 38-year-old woman presented with right milky nipple discharge.

A. US shows round, isoechoic and circumscribed mass within right nipple with vessels in rim (arrow). On MRI, mass is hyperintense on T2weighted image (B, arrow), with complete rim enhancement on MIP image (C, arrow). D. Patient received antibiotics therapy and complete lesion's resolution was noted after 10 days. MIP = maximum intensity projection

rarely require fine needle aspiration cytology.

\section{Epidermal Inclusion Cyst}

Epidermal inclusion cysts are the most common keratinous cysts of the skin (18), which arise from the sequestration of epidermal cells into the dermis through the continuous accumulation of keratin. US shows a round, hypoechoic mass with circumscribed margins and the absence of a vascular flow. Excision or percutaneous biopsy is occasionally necessary to differentiate epidermal inclusion cysts and tumors (Fig. 7).

\section{Eczema}

The prevalence of nipple and areola eczema is currently unknown. Because it typically affects both nipples, unilateral involvement of the same is rarely reported. Eczema has two forms: acute-a "wet" erythematous eruption with vesicles and sub-acute or chronic-a dry, erythematous, and lichenified dermatitis (19).

Eczema may appear as a minor manifestation of atopic dermatitis (AD). However, there are no reported differences regarding its degree of severity, inflammation pattern or immunohistochemical findings between patients with or without AD (20). US reveals skin changes, such as skin thickening and increased vascularity on color Doppler US, in the areolar region. The findings might be responsive to topical application of steroids (Fig. 8). Unilateral eczema may clinically resemble Paget's disease, but it initially involves only the areola and later progresses to the nipple. Contrarily, Paget's disease spreads outwards from the nipple. If the symptoms and US findings do not improve after steroidal administration, a biopsy to exclude Paget's disease is warranted $(2,21)$.

Other nipple pathologies may present with eczematous features, such as psoriasis, allergic contact dermatitis, and infections (Fig. 9).

\section{Leiomyoma}

Leiomyomas of the nipple-areola complex are the least common subtype of genital-leiomyomas, with only 50 
previously described cases (22). It is a slow growing benign tumor of smooth muscles and it affects one or both nipples and represents a potential cause of inflammation and chronic nipple pain (23). US shows an oval, circumscribed hypoechoic mass with internal vascularity, whereas an MRI scan reveals an intense, homogeneous enhancement in the

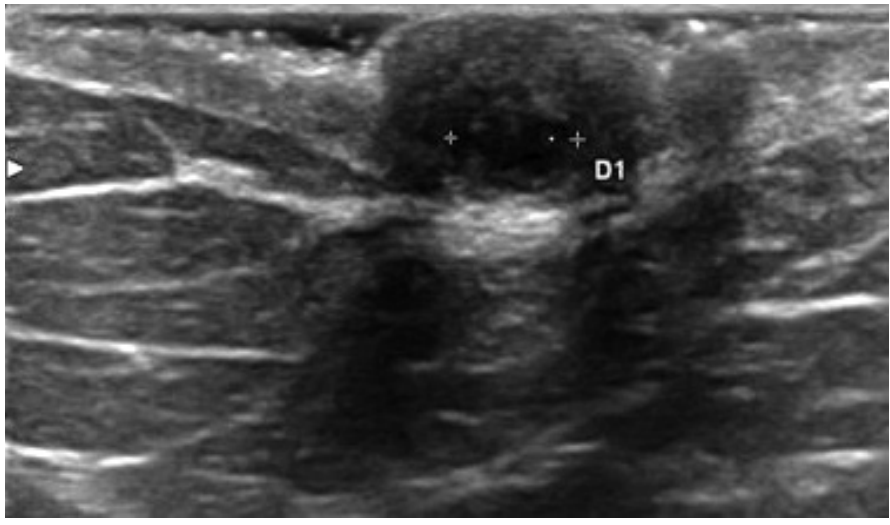

A

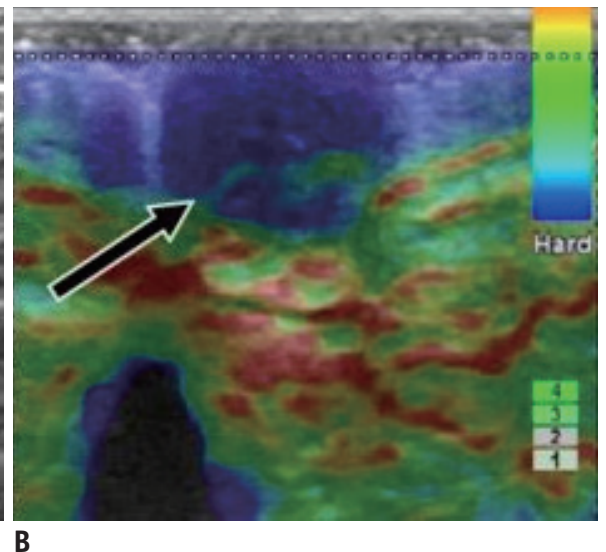

B

Fig. 7. Epidermal inclusion cyst of nipple. 43-year-old women presented with left painful nipple.

A. US reveals round, hypoechoic, circumscribed mass with acoustic enhancement located within nipple. B. Mass is more clearly delineated on elastography (arrow), latter with limited value due to lesion's superficial location.

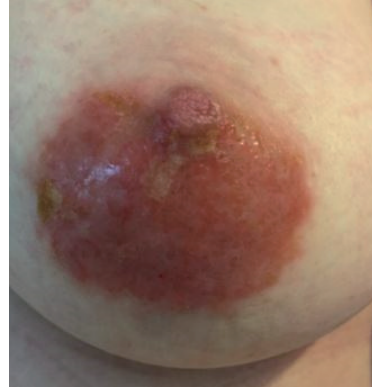

A

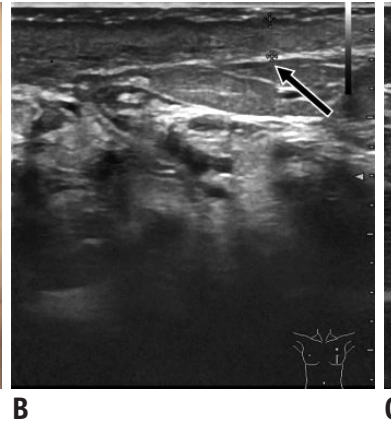

B

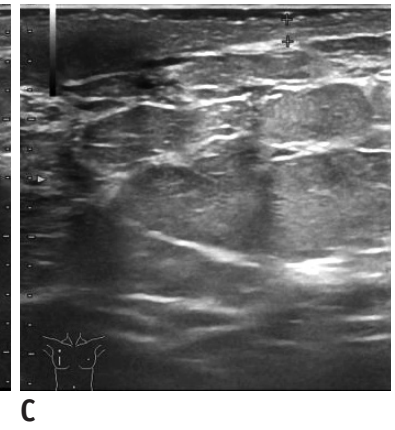

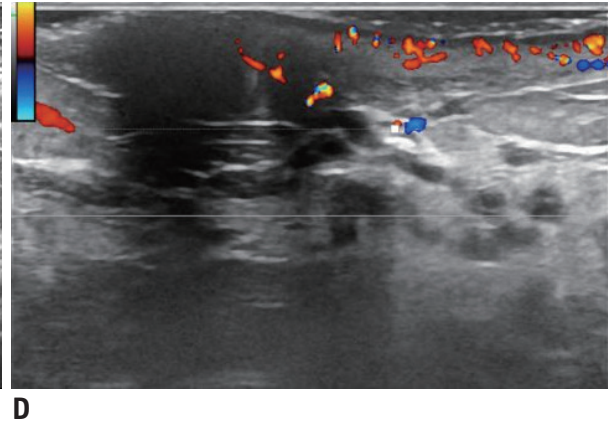

Fig. 8. Acute eczema of nipple.

A. 46-year-old woman presented with redness, small vesicles, and pain in left nipple-areola complex. US shows skin thickening on left side (B) compared with right side (C, arrow), along with increased vascularity in nipple and areola region (D). Patient's symptoms improved after 3 weeks of topical application of steroid cream.

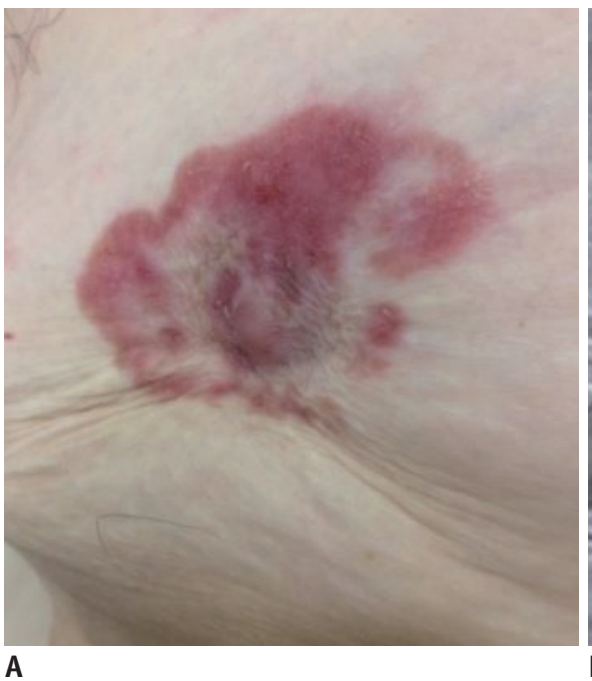

A

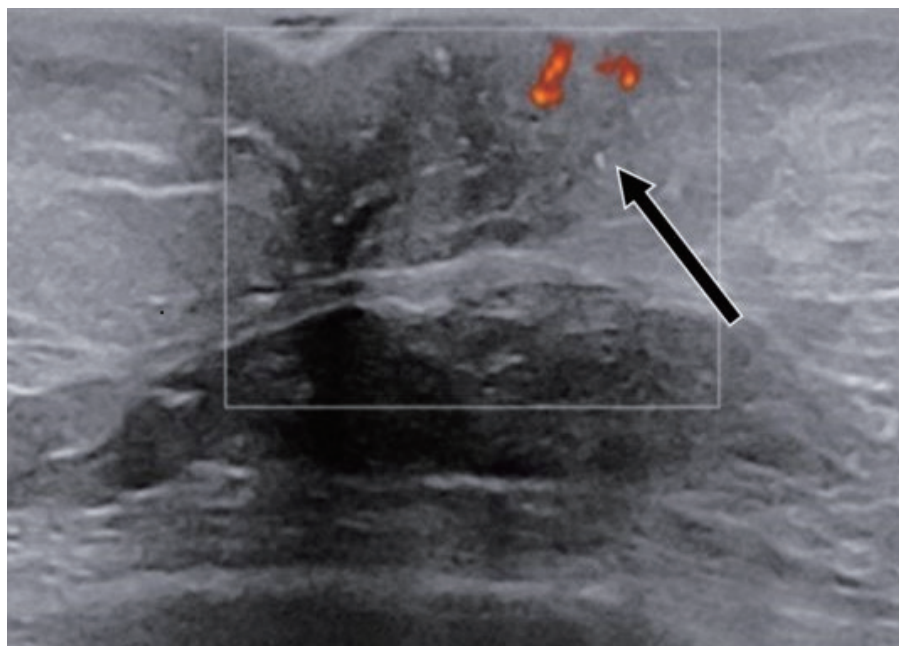

B

Fig. 9. Chronic eczema of nipple.

A. 66-year-old woman known with psoriasis, presented with red excoriations involving right nipple-areolar complex for 10 years. Patient has positive history of right breast surgery with benign histology. B. US shows nipple retraction and subtle skin thickening, with internal vascularity (arrow). 
mass (Fig. 10). Excisional biopsy is generally performed for histological confirmation.

\section{Fibroepithelial Polyp}

Fibroepithelial polyp is an extremely rare benign tumor that typically occurs in the skin, oral cavity, and genitourinary tract. Previously, there have been a few cases on nipple fibroepithelial polyps $(24,25)$. Histologically, polyps are superficial lesions covered by squamous epithelium, with spindle, stellate and stromal giant cells. It is difficult to distinguish them from metaplastic-spindle cell carcinoma based on biopsy samples alone. An MRI scan may be used to assess the polyp's extension and to plan the excisional biopsy (Fig. 11).

\section{Adenoma}

Nipple adenoma is an uncommon benign tumor with unknown prevalence. Histologically, an epithelial proliferation with a retained myoepithelial cell layer occupies the surrounding stroma of lactiferous ducts (3). Clinically, it manifests as a palpable nipple nodule or simulates Paget disease and it is rarely associated with bloody nipple discharge. It is visualized as a round, homogeneous, hypoechoic mass with circumscribed margins and intense vascularity on US (26) (Fig. 12). Nipple skin punch biopsy confirmation and subsequent surgical excision remain the gold standard to diagnose and treat adenoma, similar to all benign nipple tumors (26).
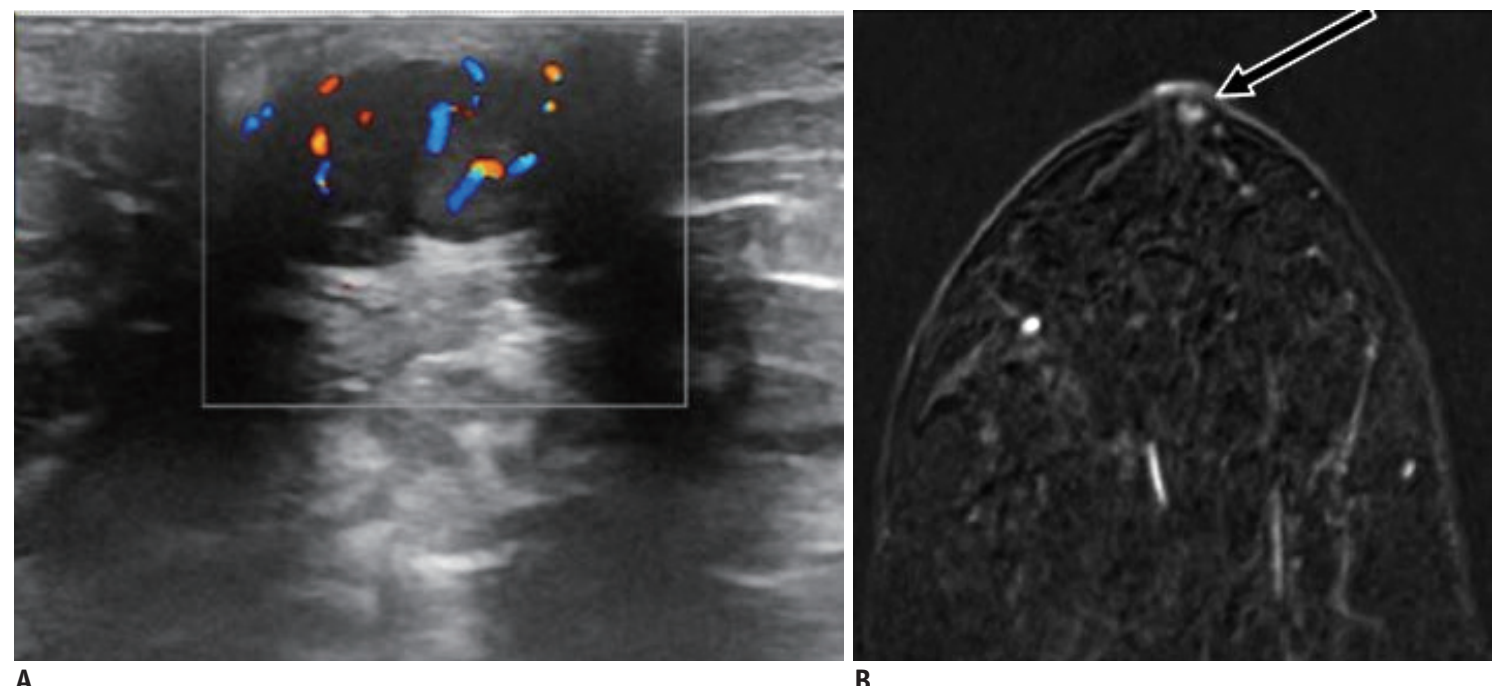

Fig. 10. Nipple leiomyoma. 48-year-old woman presented with nipple tenderness.

A. US reveals oval, hypoechoic, circumscribed mass located within nipple, with acoustic enhancement and internal vascularity. B. T1-weighted subtraction image reveals focal enhancement of nipple corresponding to US mass (arrow). Patient underwent surgery with histology result of leiomyoma.

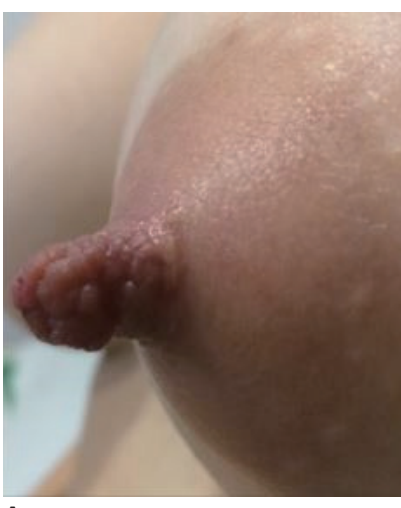

A
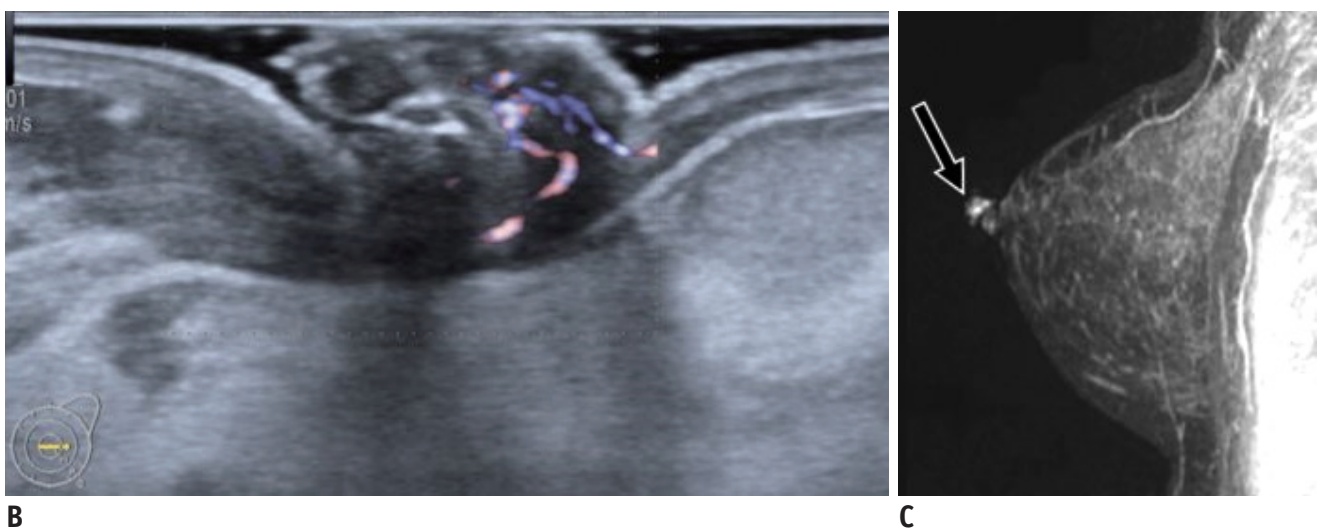

Fig. 11. Fibroepithelial polyp.

A. 25-year-old patient presented with polypoid lesion involving left nipple. B. US shows irregular, iso-/hypoechoic mass with indistinct margins and with vascular pedicle. C. On MRI, MIP images reveal mass with intense enhancement located in nipple (arrow). Consequently, surgical excision of polyp and nipple was performed. 


\section{Central Papilloma}

Intraductal papillary lesions (papilloma) are breast tumors that are observed in 2-3\% of women between ages of 30 to 77 years (27). These are classified into central and peripheral types. Central papillomas arise in the subareolar space and are usually solitary, whereas the latter tend to occur in clusters. Approximately $57 \%$ of the patients with breast papilloma present with spontaneous, unilateral, bloody nipple discharge, with a higher incidence of central papillomas. Apart from the fact that a central papilloma arises within major ducts and peripheral papilloma occupy the terminal ductules, both types demonstrate identical histological characteristics, which include an intraductal proliferation of epithelial and myoepithelial cells overlying a fibro-vascular stalk (28). Unlike adenoma secretions, which are discharged into a confined space outside the ducts, the papilloma mucus-secretions are inside the ducts $(12,21)$. The epithelial component may harbor a wide spectrum of morphologic changes ranging from hyperplasia to metaplasia, atypical intraductal hyperplasia, and in situ carcinoma (28). Compared to peripheral papilloma, a central papilloma is less associated with a coexisting malignancy (27).

Benign and malignant papillomas have similar US findings and may present as either a mass, a complex cystic-solid mass or duct changes only; all presentations show internal vascularity. MRI examinations reveal the presence or absence of a mass or non-mass enhancement (NME, focus type) depending on their size, and are rarely MRI occults (up to $2 \%$ ) (29). A mass exceeding $10 \mathrm{~mm}$, a mixed mass-NME lesion, and the segmental/regional distribution of the NME lesions are findings more commonly observed in high-risk papilloma or malignant lesions than in benign papilloma (29) (Figs. 13-15). Since imaging criteria alone are not sufficient to exclude the possibility of a malignant tumor, a percutaneous needle biopsy followed by surgical excision, is usually recommended for cases diagnosed with papilloma.

\section{Malignant Pathology}

\section{Primary Invasive Carcinomas of Nipple}

Approximately $8 \%$ of breast cancers develop within the central part of the breast (2). Two cancer types involve the nipple: primary (developing within the nipple) and secondary carcinomas (breast tumors that spread towards nipple). The amount of published information on nipple primary carcinomas is considerably lacking apart from that

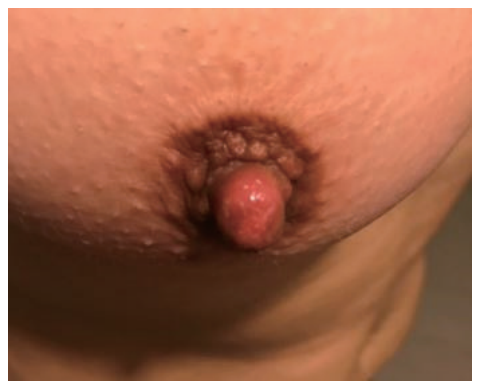

A

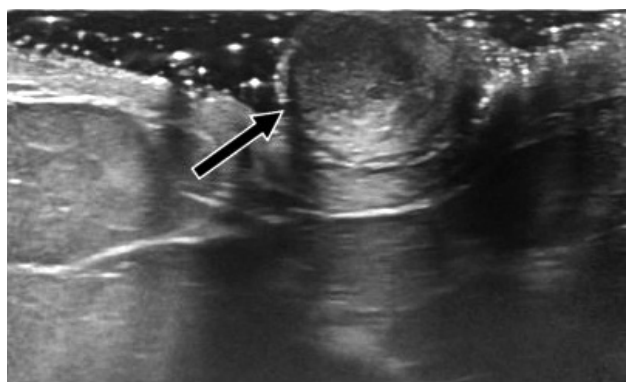

B

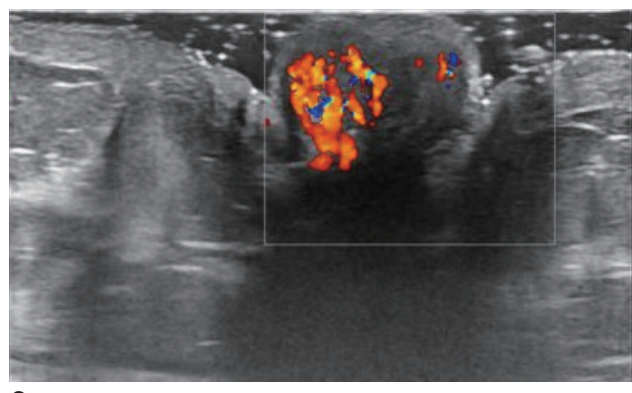

C

Fig. 12. Nipple adenoma.

A. 40-year-old woman presented with nipple erythema for 6 months. US shows round, isoechoic and circumscribed nipple mass (B, arrow), with internal vascularity (C). Patient underwent surgery with histology result of adenoma.

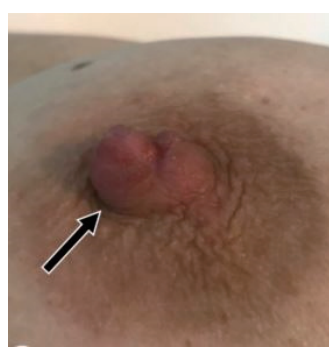

A

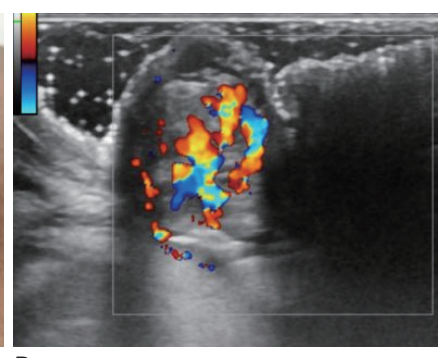

B

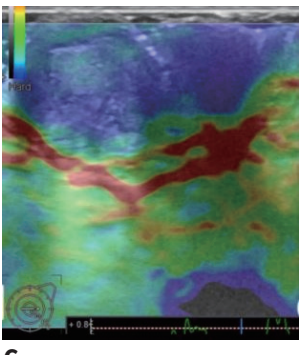

C

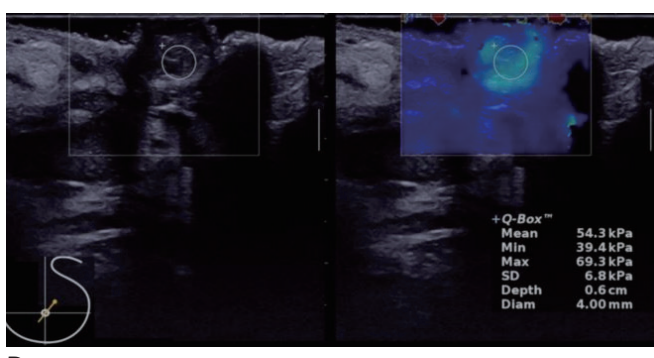

D

Fig. 13. Papilloma-mass.

A. 37-year-old patient presented with left palpable nipple nodule (arrow). B. US shows oval, isoechoic and circumscribed mass with internal vascularity. While strain elastography has limited value $($ C), shear-wave elastography reveals mass's stiffness (max stiffness $=69.3 \mathrm{kPa})($ D) Patient underwent surgery with histology result of benign papilloma. 


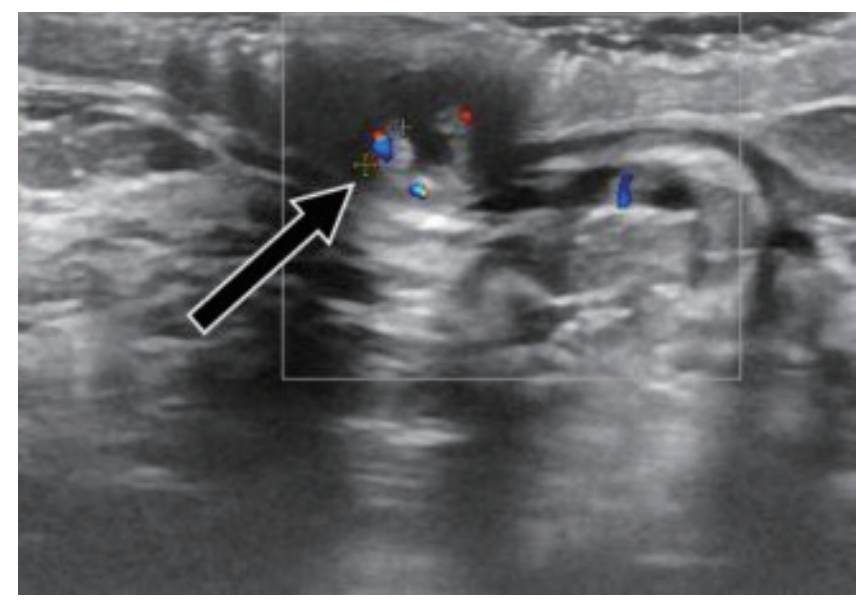

Fig. 14. Papilloma-complex cystic-solid mass. 55-year-old patient presented with bloody nipple discharge. US shows complex cystic and solid mass inside nipple and discrete retroareolar duct ectasia with hypoechoic content and internal vascularity (arrow). Patient underwent surgery, which proved that complex cystic mass and duct content were small papillomas. on Paget's disease. Nipple cancers are difficult to detect, as they are usually confused with normal nipple structures (15). A recent paper reported that $50 \%$ of the primary nipple carcinomas are ductal, $21 \%$ of them are lobular, and $29 \%$ of cancers have mixed ductal and lobular features (30).

US findings of primary ductal carcinoma in situ (DCIS) of the nipple overlap with that of benign nipple tumor masses (Figs. 16, 17).

US features of primary invasive carcinoma of the nipple are as follows: 1) swollen nipple, usually homogeneously hypoechoic with intense vascularity compared to a contralateral; 2) irregular mass with iso-/ hypoechoic echo-pattern, indistinct or spiculated margins, shadowing, and internal vascularity; 3 ) complex cystic-solid mass; 4) duct changes, with duct ectasia and intraductal microcalcifications/hypoechoic content with internal vascularity; and 5) microcalcifications (Figs. 18, 19).

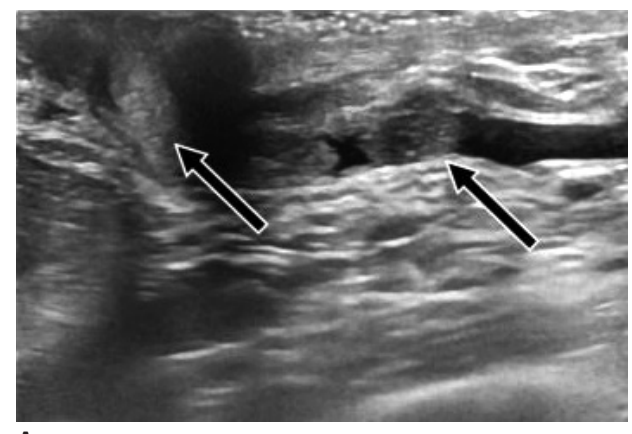

A

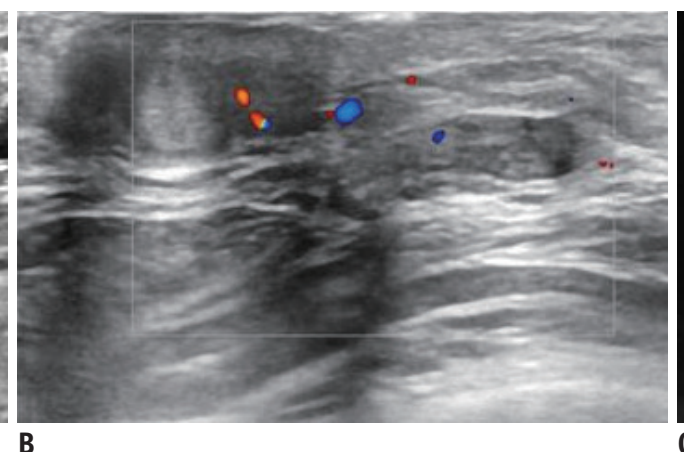

B

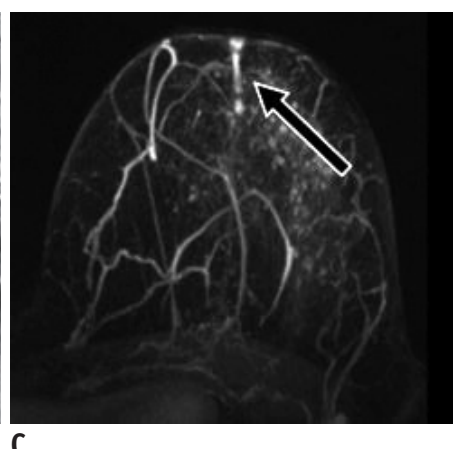

C

Fig. 15. Papilloma-intraductal mass. 46-year-old patient presented with bloody nipple discharge.

US shows nipple dilated duct with hypoechoic content, which extends into retroareolar area (A, arrows) and has intraductal vascularity (B).

C. MIP image (arrow) displays linear, non-mass enhancement corresponding to duct content. Patient underwent surgical excision of duct with histology result of papillomas.

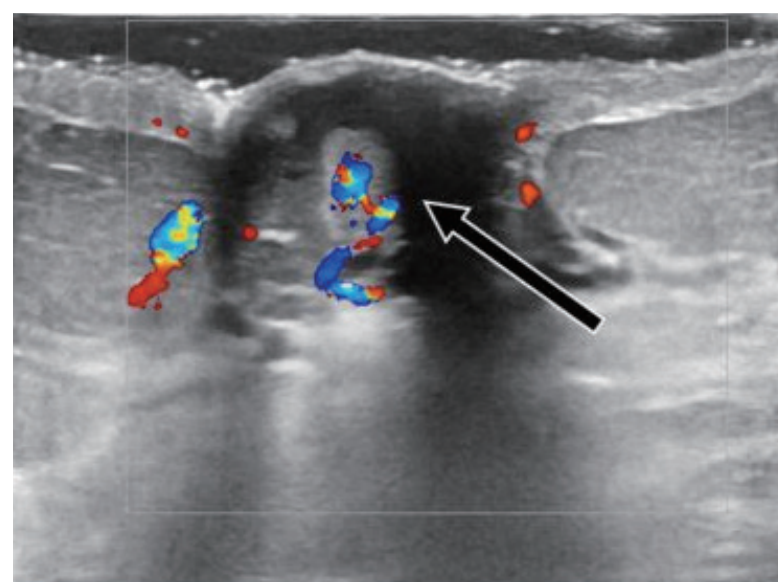

A

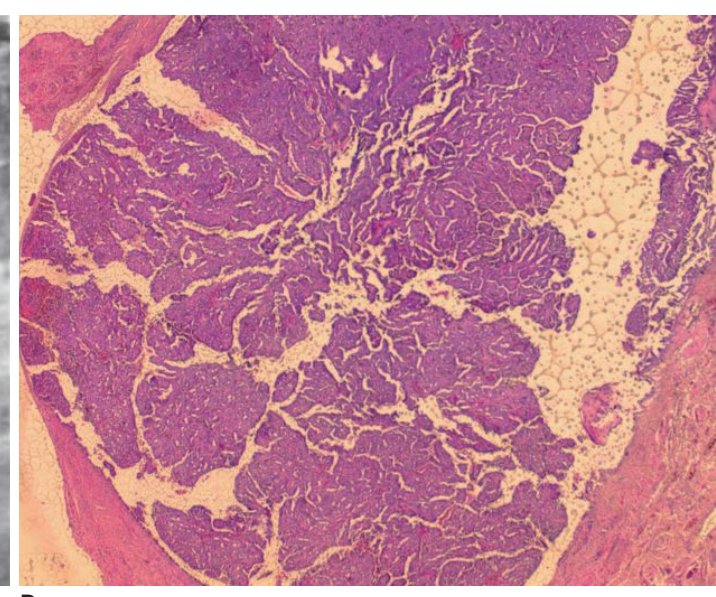

B

Fig. 16. DCIS-mass. 75-year-old patient presented with bloody nipple discharge.

A. US shows irregular, hypoechoic nipple mass with indistinct margins and internal vascularity (arrow). B. After surgery, histology (hematoxylin and eosin stain $\times 2.5$ ) reveals papillary lesion inside dilated duct, with areas of malignant transformation-DCIS with nuclear grade 2 foci. DCIS $=$ ductal carcinoma in situ 


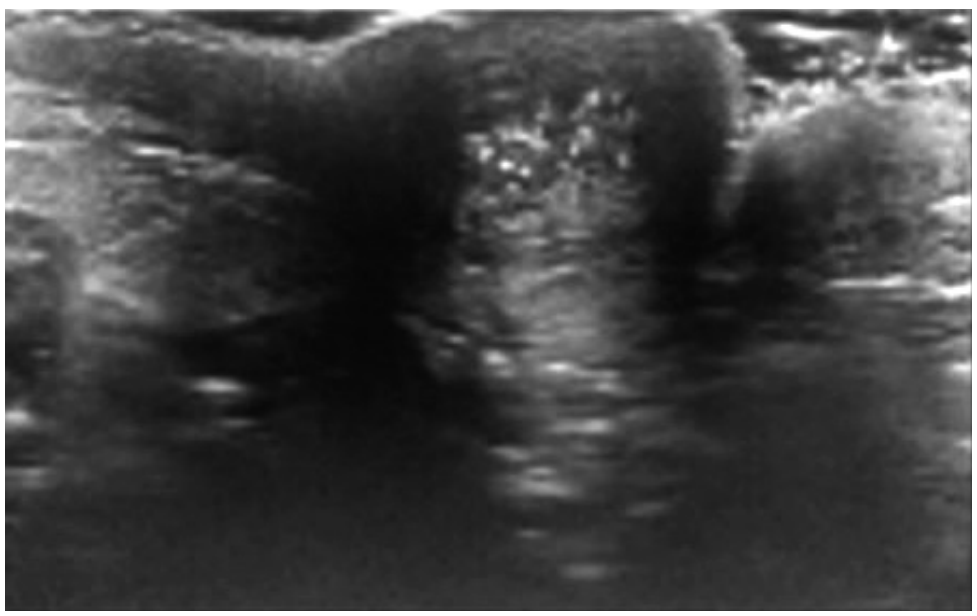

A

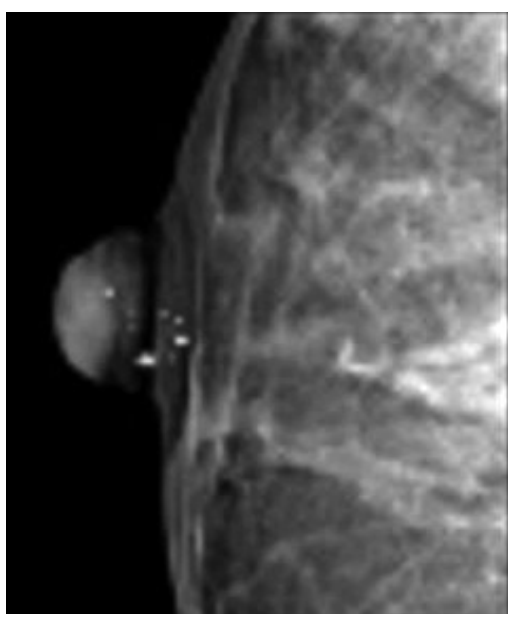

B

Fig. 17. DCIS-microcalcifications. Images of asymptomatic patient.

US shows scattered echogenic foci (A) confirmed by mammography (B) as microcalcifications. After positive MRI (not shown), patient underwent surgery with pathology result of DCIS.

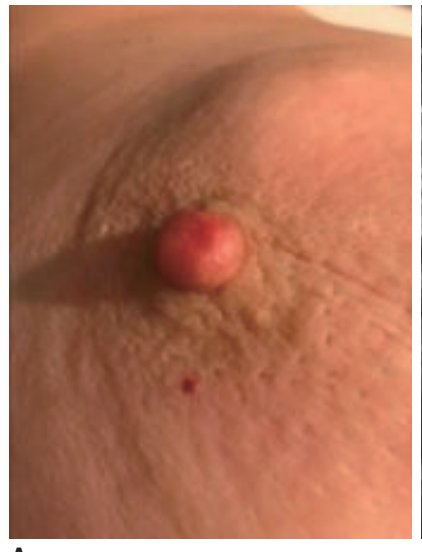

A

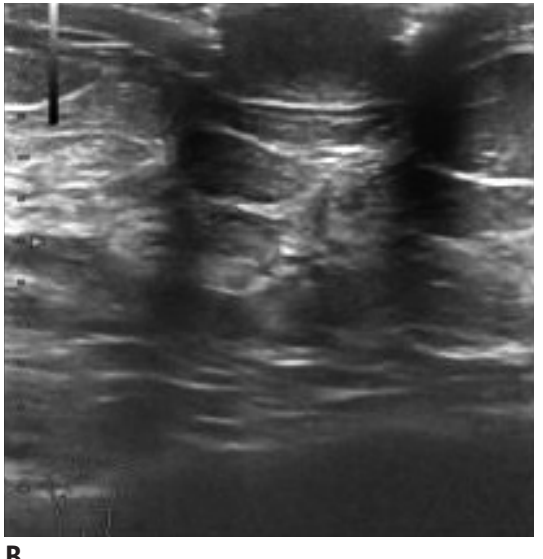

B

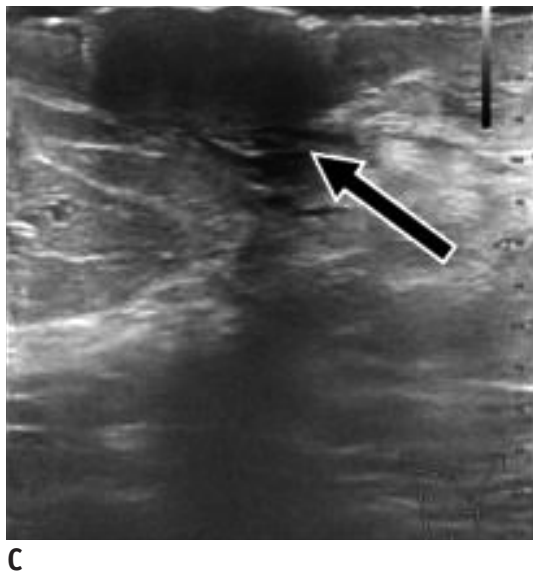

C

Fig. 18. IDC-swollen nipple.

A. 68-year-old patient presented with erosion on left swollen nipple. US reveals larger, homogeneous and hypoechoic left nipple (C, arrow) compared to right one (B). Additional suspicious mass was seen in left outer quadrant of left breast (not shown). Patient underwent surgery with pathology result of IDC no special type nuclear grade 3, estrogen receptor $=70 \%$, progesterone receptor $=30 \%$, Ki- $67=35 \%$, human epidermal growth factor receptor $2=+3$, involving nipple. IDC = invasive ductal carcinoma

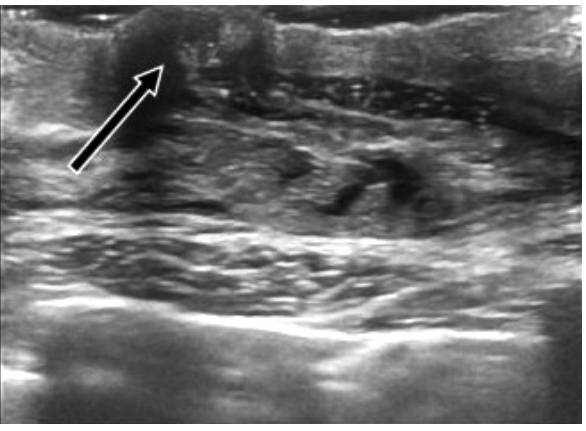

A

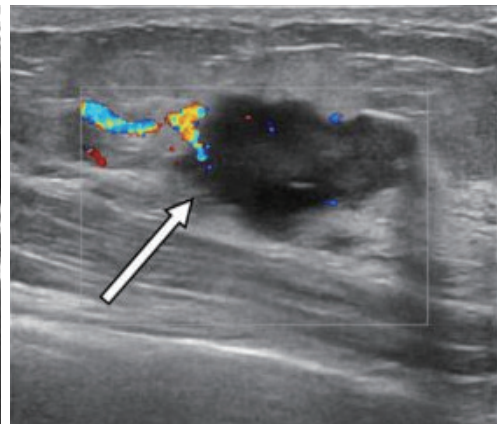

B

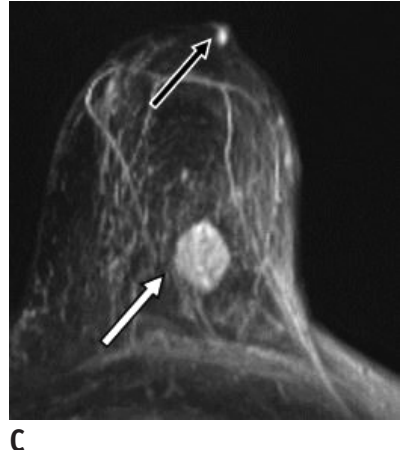

C

Fig. 19. IDC-ductal changes. 60-year-old patient presented with bloody nipple discharge.

A. US shows dilated ducts involving nipple and retroareolar region (black arrow) with hypoechoic content. Mammography (not shown) excluded presence of microcalcifications. B. Additional irregular, hypoechoic mass with indistinct margins and internal vascularity is detected in left outer quadrant of same breast (white arrow). C. MRI (arrows) identifies two US findings; small focus-type nipple lesion and the second, larger mass in outer quadrant. Histology highlighted IDC for both lesions. 

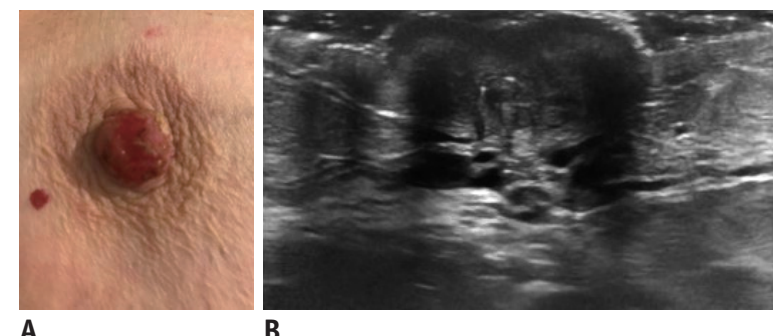

B

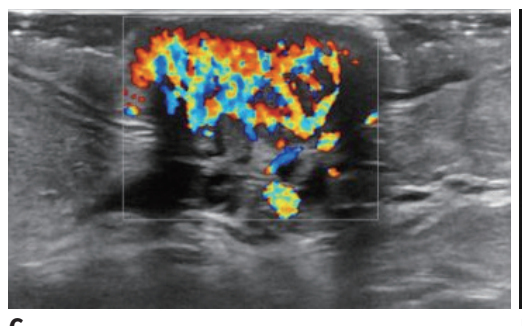

C

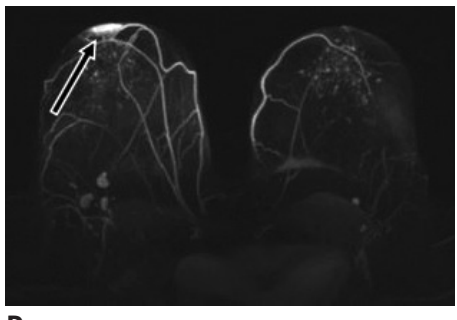

D

Fig. 20. Paget's disease.

A. 84-years-old patient presented with erosions and swollen right nipple. US reveals globally enlarged nipple (B) with internal vascularity (C).

D. MIP image highlights asymmetrical enhancement of right nipple (arrow). Punch biopsy confirmed Paget's disease of nipple.

Table 1. US Findings of Inflammatory Lesions, Benign Tumors, and Invasive Cancer of Nipple

\begin{tabular}{|c|c|c|c|}
\hline Us Findings & Inflammatory Nipple Lesion & Benign Tumor & Invasive Malignancy \\
\hline \multicolumn{4}{|l|}{ Masses } \\
\hline Shape & Round/oval & Round/oval & Irregular \\
\hline Echo-pattern & Hypo-/isoechoic & Hypo-/isoechoic & Hypoechoic \\
\hline Margins & Circumscribed/indistinct & Circumscribed & Indistinct/spiculated \\
\hline Posterior features & - & - (enhancement) & - (shadowing) \\
\hline Vascularity & + (rim vessels) & + & + \\
\hline \multicolumn{4}{|l|}{ Ductal changes } \\
\hline Dilated duct & + & + & + \\
\hline Content & +/- hypoechoic & + hypoechoic & $\begin{array}{l}\text { +/- hypoechoic } \\
\text { +/- calcifications }\end{array}$ \\
\hline Vascularity & + (periductal) & + (intraductal) & + (intraductal) \\
\hline US short-term follow-up & Completely absent/small size & No change/same size & No change/increasing size \\
\hline
\end{tabular}

US = ultrasound, + = present, - = absent

\section{Paget's Disease}

Paget's disease accounts for less than $3 \%$ of all breast carcinoma, and is characterized by the presence of malignant cells within the squamous epithelium of the nipple (19). It may consist of a single self-standing nipple malignancy, or it may be associated with DCIS and invasive carcinoma (invasive ductal carcinoma [IDC] in more than $80 \%$ of cases), both in proximity of or distant from the nipple (31).

The differential diagnoses should include other pathologies including eczema, Bowen's disease, melanoma, or breast carcinoma involving the nipple by contiguity or invasion (31).

Clinical examination may reveal subtle skin changes (erythema or ulceration) as the only sign of Paget's disease. US should be included in the initial diagnostic evaluation, especially upon a negative mammography outcome. US findings include nipple asymmetry, nipple flattening, or skin thickening, the presence of a mass, microcalcifications, or duct changes within the nipple (32). MRI is recommended in patients with Paget's disease. In addition to skin thickening and/or asymmetrical nipple enhancement, presence of underlying parenchymal DCIS or IDC should be evaluated with MRI (Fig. 20). Paget's disease is usually diagnosed on nipple punch biopsies. Surgical planning regarding the feasibility of conservative surgery is decided based on presence and extent of parenchymal DCIS or IDC on MRI.

The main imaging differences between inflammatory nipple lesion, benign tumor, and nipple malignancy are presented in Table 1. The histology and US findings of all aforementioned nipple pathologies are listed in Table 2.

\section{CONCLUSION}

Summarily, nipples may be affected by various benign and malignant pathologies, several of which have similar clinical and imaging presentations. US is the first-line imaging examination to characterize and identify nipple lesions with a non-invasive and practical approach. Appropriate US technique to evaluate nipple pathology is crucial. Inflammatory lesions often display a peripheral vascularity (periductal), while tumor masses show internal vascularity. An irregular, hypoechoic mass with spiculated margins and 
Nipple Ultrasound

Table 2. Benign and Malignant Nipple Pathologies

\begin{tabular}{|c|c|c|c|c|}
\hline \multirow[b]{2}{*}{ Pathologies } & \multirow[b]{2}{*}{ Histologic Features } & \multicolumn{2}{|l|}{ Imaging Features } & \multirow[b]{2}{*}{ Treatment } \\
\hline & & B-Mode & $\begin{array}{l}\text { Color Doppler Mode } \\
\text { (Vascularity) }\end{array}$ & \\
\hline Duct ectasia & $\begin{array}{l}\text { Nonspecific duct dilatation } \\
(>2 \mathrm{~mm})\end{array}$ & Duct changes & - & $\begin{array}{l}\text { Antibiotics, } \\
\text { duct excision }\end{array}$ \\
\hline Abscess & Localized collection of pus & Circumscribed/non-circumscribed mass & $+($ vessels in rim) & Antibiotics \\
\hline Epidermal inclusion cyst & Keratin containing cyst & Circumscribed mass + enhancement & - & Surgery \\
\hline Eczema & $\begin{array}{l}\text { Skin edema and perivascular } \\
\text { lymphocytic infiltration }\end{array}$ & Thickening of skin $>2 \mathrm{~mm}$ & + & Topical steroids \\
\hline Leiomyoma & $\begin{array}{l}\text { Smooth muscle cell benign } \\
\text { tumor }\end{array}$ & Circumscribed mass + enhancement & + & Surgery \\
\hline Fibroepithelial polyp & Superficial polyp & Mass on skin & + (vascular pedicle) & Surgery \\
\hline Adenoma & $\begin{array}{l}\text { Benign epithelial } \\
\text { proliferation located } \\
\text { outside ducts }\end{array}$ & $\begin{array}{l}\text { Circumscribed/non-circumscribed mass } \\
+ \text { enhancement }\end{array}$ & + & Surgery \\
\hline Papilloma & $\begin{array}{l}\text { Benign intraductal epithelial } \\
\text { proliferation }\end{array}$ & $\begin{array}{l}\text { - Circumscribed mass } \\
\text { - Complex cystic-solid mass } \\
\text { - Duct changes }\end{array}$ & $\begin{array}{l}+ \\
+ \\
+\end{array}$ & Surgery \\
\hline $\begin{array}{l}\text { Invasive primary } \\
\text { carcinomas }\end{array}$ & $\begin{array}{l}\text { In situ/invasive carcinomas } \\
\text { - malignant cells } \\
\text { originating in ducts }(50 \%) \text {, } \\
\text { lobules }(21 \%) \text { or both } \\
(29 \%)\end{array}$ & $\begin{array}{l}\text { - Swollen nipple* } \\
\text { - Non-circumscribed mass +/- shadowing } \\
\text { - Complex cystic-solid mass } \\
\text { - Duct changes } \\
\text { - Microcalcifications }\end{array}$ & $\begin{array}{l}+ \\
+ \\
+ \\
+ \\
-\end{array}$ & $\begin{array}{l}\text { Surgery +/- } \\
\text { Chemo-/ } \\
\text { Radiotherapy }\end{array}$ \\
\hline Paget's disease & $\begin{array}{l}\text { Malignant cells within } \\
\text { squamous epithelium of } \\
\text { nipple }\end{array}$ & $\begin{array}{l}\text { - Nipple asymmetry +/- nipple flattening } \\
+/ \text { - skin thickening } \\
\text { - Non-circumscribed mass } \\
\text { - Duct changes } \\
\text { - Microcalcifications }\end{array}$ & $\begin{array}{l}+* \\
+ \\
+ \\
-\end{array}$ & $\begin{array}{l}\text { Surgery +/- } \\
\text { Radiotherapy }\end{array}$ \\
\hline
\end{tabular}

*Findings compared to contralateral nipple. + = internal vascularity present, - = internal vascularity absent

shadowing in nipple suggests the possibility of invasive carcinoma of the nipple. DCIS and benign tumors (papilloma, adenoma) have overlapping US findings.

\section{Conflicts of Interest}

The authors have no potential conflicts of interest to disclose.

ORCID iDs

Roxana Maria Pintican

https://orcid.org/0000-0002-2222-3219

Angelica Chiorean

https://orcid.org/0000-0003-1322-1470

Diana Feier

https://orcid.org/0000-0001-7018-5045

Bogdan Fetica

https://orcid.org/0000-0001-8640-7546
George Dindelegan

https://orcid.org/0000-0003-1485-6654

Bura Vlad

https://orcid.org/0000-0001-9674-2671

Magdalena Duma

https://orcid.org/0000-0001-7657-2222

\section{REFERENCES}

1. Pandya S, Moore RG. Breast development and anatomy. Clin Obstet Gynecol 2011;54:91-95

2. Nicholson BT, Harvey JA, Cohen MA. Nipple-areolar complex: normal anatomy and benign and malignant processes.

Radiographics 2009;29:509-523

3. Patel BK, Falcon S, Drukteinis J. Management of nipple discharge and the associated imaging findings. $\mathrm{Am} \mathrm{J}$ Med 2015;128:353-360

4. Waldman RA, Finch J, Grant-Kels JM, Stevenson C, WhitakerWorth D. Skin diseases of the breast and nipple: benign and 
malignant tumors. J Am Acad Dermatol 2019;80:1467-1481

5. Robertson FM, Bondy M, Yang W, Yamauchi H, Wiggins S, Kamrudin $S$, et al. Inflammatory breast cancer: the disease, the biology, the treatment. CA Cancer J Clin 2010;60:351-375

6. Bahl M, Gadd MA, Lehman CD. Journal Club: diagnostic utility of MRI after negative or inconclusive mammography for the evaluation of pathologic nipple discharge. AJR Am J Roentgenol 2017;209:1404-1410

7. Yılmaz R, Bender Ö, Çelik Yabul F, Dursun M, Tunacı M, Acunas $G$. Diagnosis of nipple discharge: value of magnetic resonance imaging and ultrasonography in comparison with ductoscopy. Balkan Med J 2017;34:119-126

8. Bahl M, Baker JA, Greenup RA, Ghate SV. Diagnostic value of ultrasound in female patients with nipple discharge. AJR Am J Roentgenol 2015;205:203-208

9. Lubina N, Schedelbeck U, Roth A, Weng AM, Geissinger E, Hönig $A$, et al. 3.0 tesla breast magnetic resonance imaging in patients with nipple discharge when mammography and ultrasound fail. Eur Radiol 2015;25:1285-1293

10. Hooley RJ, Scoutt LM, Philpotts LE. Breast ultrasonography: state of the art. Radiology 2013;268:642-659

11. Stavros AT. Breast anatomy: the basis for understanding sonography. In: Stavros AT, ed. Breast ultrasound. Philadelphia: Lippincott Williams \& Wilkins, 2004:56-108

12. Yoon JH, Yoon H, Kim EK, Moon HJ, Park YV, Kim MJ. Ultrasonographic evaluation of women with pathologic nipple discharge. Ultrasonography 2017;36:310-320

13. Lee SH, Chang JM, Cho N, Koo HR, Yi A, Kim SJ, et al. Practice guideline for the performance of breast ultrasound elastography. Ultrasonography 2014;33:3-10

14. Lee SH, Chang JM, Kim WH, Bae MS, Seo M, Koo HR, et al. Added value of shear-wave elastography for evaluation of breast masses detected with screening US imaging. Radiology 2014;273:61-69

15. Yu JH, Kim MJ, Cho H, Liu HJ, Han SJ, Ahn TG. Breast diseases during pregnancy and lactation. Obstet Gynecol Sci 2013;56:143-159

16. Tiu CM, Chiou SY, Chou YH, Lai CH, Chiou HJ, Chiang HR, et al. Clinical significance of ductal dilatation on breast ultrasonogram. J Med Ultrasound 2005;13:127-134

17. Dixon JM. Breast infection. BMJ 2013;347:f3291

18. Dilek N, Dilek AR, Saral Y, Sehitoğlu I. Epidermoid cyst on the nipple: a rare location. Breast J 2014;20:203-204

19. Geffroy D, Doutriaux-Dumoulins I. Clinical abnormalities of the nipple-areola complex: the role of imaging. Diagn Interv Imaging 2015;96:1033-1044

20. Song HS, Jung SE, Kim YC, Lee ES. Nipple eczema, an indicative manifestation of atopic dermatitis? A clinical, histological, and immunohistochemical study. Am J Dermatopathol 2015;37:284-288

21. Da Costa D, Taddese A, Cure ML, Gerson D, Poppiti R Jr, Esserman LE. Common and unusual diseases of the nippleareolar complex. Radiographics 2007;27 Suppl 1:S65-S77

22. Gokdemir G, Sakiz D, Koslu A. Multiple cutaneous leiomyomas of the nipple. J Eur Acad Dermatol Venereol 2006;20:468-469

23. Nakamura S, Hashimoto Y, Takeda K, Nishi K, Ishida-Yamamoto A, Mizumoto $T$, et al. Two cases of male nipple leiomyoma: idiopathic leiomyoma and gynecomastia-associated leiomyoma. Am J Dermatopathol 2012;34:287-291

24. Shaaban AM, Turton EP, Merchant W. An unusual case of a large fibroepithelial stromal polyp presenting as a nipple mass. BMC Res Notes 2013;6:345

25. Belli AK, Somuncu E, Aydogan T, Bakkaloglu D, Ilvan S, Aydogan F. Fibroepithelial polyp of the nipple in a woman. Breast J 2013;19:111-112

26. Spohn GP, Trotter SC, Tozbikian G, Povoski SP. Nipple adenoma in a female patient presenting with persistent erythema of the right nipple skin: case report, review of the literature, clinical implications, and relevancy to health care providers who evaluate and treat patients with dermatologic conditions of the breast skin. BMC Dermatol 2016;16:4

27. Ganesan S, Karthik G, Joshi M, Damodaran V. Ultrasound spectrum in intraductal papillary neoplasms of breast. $\mathrm{Br} \mathrm{J}$ Radiol 2006;79:843-849

28. Oyama T, Koerner FC. Noninvasive papillary proliferations. Semin Diagn Pathol 2004;21:32-41

29. Wang LJ, Wu P, Li XX, Luo R, Wang DB, Guan WB. Magnetic resonance imaging features for differentiating breast papilloma with high-risk or malignant lesions from benign papilloma: a retrospective study on 158 patients. World J Surg Oncol 2018;16:234

30. Sanders MA, Brock JE, Harrison BT, Wieczorek TJ, Hong X, Guidi $A J$, et al. Nipple-invasive primary carcinomas: clinical, imaging, and pathologic features of breast carcinomas originating in the nipple. Arch Pathol Lab Med 2018;142:598605

31. Geffroy D, Doutriaux-Dumoulins I, Labbe-Devilliers C, Meingan P, Houdebine S, Sagan C, et al. [Paget's disease of the nipple and differential diagnosis.] J Radiol 2011;92:889-898

32. Lim HS, Jeong SJ, Lee JS, Park MH, Kim JW, Shin SS, et al. Paget disease of the breast: mammographic, US, and MR imaging findings with pathologic correlation. Radiographics 2011;31:1973-1987 